\title{
A importância das rádios e TVs universitárias como laboratórios*
}

\author{
Edson Luiz Spenthof**
}

\section{Resumo}

O artigo trata do uso didático do rádio e da televisão universitários no ensino de comunicação. $\mathrm{O}$ autor discute o processo democrático na comunicação e a questão dos laboratórios na faculdade.

Palavras-chave: rádio e TV universitários; laboratórios; ensino de comunicação; comunicação democrática.

\section{Introdução}

A meu ver, há quatro funções básicas que explicam e justificam a existência das rádios e TVs universitárias: a divulgação da produção universitária, a canalização da política de extensão das universidades, a atividade laboratorial e a democratização da comunicação e do conhecimento.

* Palestra proferida na Universidade Federal de Pernambuco, no Cobrecos - Congresso Brasileiro dos Estudantes de Comunicação Social, em 19.01.1998 (versão compacta). Este texto é fruto da reflexão sobre o trabalho que desenvolvo na Rádio Universitária desde 1996 e de algumas discussões, no segundo semestre de 1996, com os professores Nilton José dos Reis Rocha (Jornalismo), Venerando Ribeiro de Campos (Radialismo), Maria de Fátima Garbellini (Biblioteconomia) e Divina Marques (Relações Públicas), da Faculdade de Comunicação e Biblioteconomia da UFG. Ainda que divida com eles o crédito de algumas considerações, os erros pela articulação do conjunto do texto devem ser debitados exclusivamente ao Autor.

** Jornalista, mestre em História, professor e coordenador do Laboratório Rádio Universitária da Faculdade de Comunicação e Biblioteconomia da Universidade Federal de Goiás.

Comun. inf., v.1, n. 1, p. 153-166, jan./jun. 1998 


\section{As rádios e TVs universitárias e a divulgação da produção universitária}

Um importante papel que as rádios e TVs universitárias têm de cumprir é a divulgação da produção das universidades. Evidentemente, esta divulgação não tem que ter o caráter de assessoria de imprensa. Esta função cabe ao órgão próprio da universidade (a assessoria de comunicação). Essa importância cresce à medida que se intensificam os ataques ao ensino superior e, principalmente, ao ensino superior público e gratuito. As universidades federais passam por ataques nunca antes vistos, arquitetados por aqueles que querem a sua privatização. Neste quadro, são muitas vezes infrutíferas as tentativas das instituições em contrapor uma versão alternativa à oficial. É sabido por todos nós que as universidades públicas produzem muito e com qualidade. E estas informações precisam chegar à população.

Divulgar as ações da reitoria também é algo necessário, porque, afinal, se trata de tornar público como a instituição social está sendo administrada. Todavia, o tratamento, na emissora, tem de ser preponderantemente o jornalístico. A emissora pertence à sociedade. E a população não deve ser desrespeitada com bombardeios diários de narcisismos que nada acrescentem à melhoria de sua condição de vida.

\section{As rádios e TVs universitárias e a política de extensão das universidades}

Divulgar a produção universitária por intermédio dos seus meios de comunicação é diferente de utilizá-los como veículos de uma política de extensão universitária. Se o primeiro ato representa apenas levar à, o segundo significa envolver. No primeiro caso temos uma via de mão quase única. O retorno, feedback, quando existe, é apenas no sentido de a sociedade perceber que tem um determinado serviço do qual pode lançar mão. No segundo caso, a comunidade participa efetivamente ou deve participar do processo.

Aqui não há como não nos valermos do conceito de Paulo Freire, formulado em Extensão ou comunicação? ${ }^{1}$. Fundamentalmen-

Comun. inf., v.1, n. 1, p. 153-166, jan./jun. 1998 
te, por meio do conceito da dialogicidade, Freire nos ensina que o trabalho de extensão é, e tem de ser, um diálogo. E diálogo, de $d i$, (dois), é diferente de monólogo, de mono (um). Significa que há uma ação e uma reação. Mais do que isso: há uma inter-ação.

Transportado para o nosso caso, temos que a extensão é um trabalho que envolve a comunidade na produção de um conhecimento novo, originário da experiência do professor, do estudante $\mathrm{e}$ dos representantes da comunidade envolvidos.

Forçando a barra, também podemos adaptar aqui um pouco do conceito de Habermas, desenvolvido em Teoria da Ação Comunicativa $^{2}$. A dialogicidade de Freire assemelha-se à intersubjetividade de Habermas. Este, analisando as perspectivas para a sociedade, faz uma revisão do que muitos chamam de pessimismo de seus colegas da Escola de Frankfurt - Adorno e Horckheimer - e conclui que há uma luz no fim do túnel para a sociedade, e que esta luz está no mundo vivido (sociedade civil). Especificamente, na capacidade e possibilidade da troca intersubjetiva (troca de subjetividades) que se opera na vida (mundo vivido) das pessoas, comunidades etc, visando ao estabelecimento de um consenso. E esta troca de subjetividades (impressões, expectativas, experiências, conhecimentos) se dá exatamente no diálogo ou na conversação que envolve muitas pessoas. De qualquer forma, é uma troca, e não uma mera extensão, e pode resultar em algo novo e bom para pequenas comunidades e para a humanidade como um todo.

Mas como fazer isso em veículos (rádio ou TV) tradicionalmente vias de mão única? Este é, primeiro, um desafio que se coloca. É preciso, não só por causa da extensão, mas por conta da qualidade da comunicação, tornar os nossos veículos vias de mão dupla, ou de múltiplas vias. Segundo, não estamos tateando no escuro. É possível já apontar possibilidades claras neste sentido.

Um bom exemplo são projetos educativos via rádio ou televisão. É possível fazê-los com envolvimento de comunidades específicas, buscando entender as suas carências e as suas linguagens, com profissionais e estudantes da área da Educação e Pedagogia, transformando o rádio e a TV em meios de discussão e difusão da mensagem. O produto final 


\section{6}

será um aprimoramento de conhecimentos para todos os envolvidos.

E, ainda, por que não termos trabalhos de extensão cujo tema final seja a própria comunicação? Quantas comunidades não necessitam especificamente deste tipo de trabalho e quantos cursos de comunicação não necessitam deste contato com a comunidade para trabalhar o aprendizado de uma forma de comunicação que consiga penetrar no universo popular, que capte $\mathrm{e}$ entenda esta realidade?

\section{As rádios e TVs universitárias e a política laboratorial}

Segundo Aurélio Buarque de Holanda ${ }^{3}$, laboratório é "lugar destinado ao estudo experimental de qualquer ramo da ciência, ou à aplicação dos conhecimentos científicos com objetivo prático. Teatro de notáveis operações ou transformações...".

Destas definições, podemos deduzir que a atividade laboratorial, acadêmica é o exercício de experimentação, de aplicação de conhecimentos, de atividades práticas; é realização de "notáveis operações" e "transformações" na formação e no mundo do estudante.

Podemos concluir, também, que laboratório não é só lugar (espaço físico), ou sala técnica. Mas, principalmente, espaço, ambiente (físico ou não), ou meio/instrumento/veículo no e por meio do qual se realiza a atividade laboratorial. Pode ser um estúdio de TV (lugar, sala, equipamento) ou um boletim informativo (meio, instrumento, veículo).

José Marques de Mello ${ }^{4}$ faz a distinção entre conjunto de equipamentos (espaço físico) ou atividade experimental (espaço pedagógico). Aos primeiros chama de meios e aos segundos, fins, alertando para a confusão que, por razões as mais diversas (mas não pedagógicas), se faz entre meios e fins. Para Marques, os erros - transformar os meios em fins -- só ocorrem na ausência de uma política pedagógica global de cursos e de laboratórios, em particular.

A premissa básica, portanto, para o embasamento de uma política laboratorial não deve ser o lugar, mas a atividade. Procedendo desta maneira, estaremos refletindo sobre o que temos e o que não temos e, eventualmente, precisaríamos ter. 
A rádio, ou a TV, universitária não é só um conjunto de condições físicas (salas e equipamentos) necessária à produção radiofônica ou de TV. Ela não é só um estúdio; é um veículo que, além de permitir esta produção, a transporta à sociedade, funcionando como mediadora da relação entre os produtores e o público, real, concreto.

E é exatamente esta característica - a mediação com o público - que a torna um laboratório privilegiado para as faculdades. Além disso, têm estrutura física (equipamentos, salas) e funcional (recursos humanos, estrutura jurídica e administrativa etc.) para isso. E como veículos de comunicação de massa, com esta característica essencial - a relação com o público --, permitem um extraordinário exercício prático ao conjunto dos estudantes de comunicação, nos seguintes aspectos:

\subsection{A qualidade da produção prática no âmbito das disciplinas:}

Os laboratórios que não emitem sinais, aqueles que são apenas estúdios, e não emissoras, já são importantes para o aprendizado, na medida em que permitem o exercício, a experimentação, desde o texto até a edição final. Todavia, perdem muito para os laboratórios-emissoras, porque o público, geralmente, é só o professor da disciplina, ou são alguns colegas. Falta o feedback da massa, que não só motiva a produção, como a aprimora, por diversas razões que serão aqui detalhadas.

A superação dos limites de uma disciplina (depuração dos recursos técnicos - texto, voz, edição de materiais sonoros, interpretação etc):

Uma característica importante do aprendizado é a repetição dos experimentos; em outras palavras, o exercício constante e sistemático. Há necessidade, portanto, de um laboratório que permita ao estudante um exercício extra-sala de aula, não só por um tempo, mas com uma constância satisfatória. E este laboratório, para os estudantes de Comunicação, na UFG, pelas características já apontadas, é a Rádio Universitária.

Texto, criação de programas, interpretação dos textos, conjugação de textos e elementos sonoros, multiplicidade de

Comun. inf., v.1, n. 1, p. 153-166, jan.jun. 1998 
funções etc. Tudo isso se depura num ambiente que permite a repetição dos experimentos, com as devidas correções de rumo.

\subsection{A multidisciplinaridade e a interdisciplinaridade}

A rádio ou a TV universitária podem funcionar como um aglutinador das necessidades de várias disciplinas e cursos, procurando dar vazão a uma demanda por experimentação. Funciona como um espaço multidisciplinar de reforço pedagógico da proposta curricular da faculdade. Mais: passa, com esta característica, a fazer parte desta proposta pedagógica global, e assim deve ser entendida.

Por ter esta relação com o público e por possuir uma determinada estrutura, em alguns casos invejável até para os padrões comerciais, a emissora permite que tanto estudantes de áreas tradicionalmente ligadas ao meio rádio, como Jornalismo e Radialismo, quanto os de áreas afins (Propaganda e Publicidade, Biblioteconomia e Relações Públicas), convivam em um único e multidisciplinar ambiente de produção. É possível e salutar, até mesmo ampliar esta multidisciplinaridade, incluindo outras áreas, como Educação, Artes (Música, Artes Cênicas etc), Letras, Ciências Sociais.

A multidisciplinaridade é entendida, aqui, portanto, como a convivência destas diversas áreas e disciplinas para a realização, de forma complementar, de um projeto de formação de profissionais e de cidadãos. Mas a rádio e a TV abrem espaço, também, e de forma muito rica, para a produção interdisciplinar. Esta é entendida como a fusão de conhecimentos e de experiências, bem como a fusão, em uma única equipe, de produtores destas diversas áreas e disciplinas. É, naturalmente, mais difícil conceituar a interdisciplinaridade do que a multidisciplinaridade e, mais ainda, estabelecer os limites na aplicação prática.

Não obstante estas dificuldades, é preciso destacar que entre algumas áreas a interdisciplinaridade não só é possível, como já foi testada no laboratório Rádio Universitária da UFG, com resultado altamente compensador.

Comun. inf., v.1, n. 1, p. 153-166, jan./jun. 1998 


\subsection{O confronto com a velocidade da informação}

Neste campo, os laboratórios-emissoras dão uma das mais importantes contribuições para o processo ensino-aprendizagem. É sabido que a profissão de comunicador social (nas suas diversas habilitações) exige uma elevada capacidade de levanta-mento de informações e a sua transformação em produto final (notícia, peça publicitária, release etc) dentro de um curto espaço de tempo. A pressão do dia-a dia é marca registrada das profissões, inclusive com os tradicionais exageros, que têm levado estes profissionais a esgotamentos físicos e mentais precoces. O lado positivo desta realidade de mercado pode ser integralmente reproduzido na emissora, e tem sido na Universitária da UFG, com programas diários e semanais.

\subsection{O feedback}

Como fazer laboratório sem a opinião daqueles a quem se destinam os experimentos: o público-alvo? O público dá esse feedback. Tendo este retorno, há, desde cedo (desde a condição de estudante), um esmero infinitamente maior por parte de quem produz algo para ser veiculado. Isso significa que a Rádio e a TV adquirem a conotação de um verdadeiro laboratório de ética, pois a preocupação com a veracidade, com a correspondência entre o material preparado pelo estudante. comunicador para veiculação e a realidade dos fatos passa a ser uma constante na vida deste estudante. As possíveis distorções na divulgação das informações tendem a ser cobradas de imediato de seu autor, quer pelos colegas de trabalho, também mais atentos, quer, e principalmente, pelo público ouvinte, que não raras vezes telefona para manifestar seu pensamento ou corrigir dados, e pela própria fonte consultada para a obtenção das informações, que alerta, pressiona e ameaça, inclusive judicialmente, o repórter que incorre em erro. É possível, também, comparar esta prática com o que é ensinado em sala de aula e enriquecer a ambas: teoria e prática.

Outro aspecto importante a ressaltar, aqui, é que pelas características da emissora é possível ao aluno competir no mer-

Comun. inf., v.1, n. 1, p. 153-166, jan./jun. 1998 
cado com outra versão dos fatos, livre das restrições econômicas e políticas que normalmente impedem que os veículos comerciais se preocupem com a maioria da sociedade, privilegiando assuntos e enfoques que interessem à classe hegemônica $\mathrm{e}$ às fontes oficiais. Isso permite o desenvolvimento do senso crítico/profissional do aluno, pois está, já na condição de estudante, relacionando-se com este mercado e podendo comparar diferentes maneiras de fazer e interesses que estão em jogo, neste mercado, se assim se pode dizer, da informação.

Essa relação com o mercado também transforma o laboratório numa grande vitrine para os estudantes da Facomb/UFG. Recém-egressos da Faculdade costumam ser admitidos com a maior facilidade assim que comprovam passagem pela Rádio Universitária da UFG.

Outro fator importante a ressaltar nesta relação com o mercado é que isso permite um contato maior com as novidades que este mercado apresenta, no tocante às novas tecnologias, às formas de produção, à linguagem etc.

\section{5 $O$ papel da Universidade na oferta de oportunidades de aprendizado}

Muito tem sido dito a respeito do papel da Universidade na intermediação das relações entre o estudante e o mercado de trabalho. Para muitos, isso se resolve com a simples instituição de uma política de estágios, em parceria, exatamente, com alguns setores deste mercado. Esta concepção cria uma distorção: privilegia-se o estágio e negligencia-se o laboratório. Sem entrar na histórica polêmica sobre o estágio, que tem consumido boa parte do tempo do segmento Jornalismo nos últimos 20 anos sem apontar se o estágio deve ou não ser legalizado, é inegável que a preocupação primeira de um centro de formação de profissionais é ele mesmo se incumbir desta tarefa. À parte seus próprios vícios, um centro educacional está, naturalmente, livre daqueles proporcionados pelas pressões naturais do mercado de trabalho. A questão fundamental, no entanto, é que o mercado não está estruturado para ensinar; esta não é a sua finalidade (ele se estrutura para o lucro), mas sim a de um centro educacional.

Comun. inf., v.1, n. 1, p. 153-166, jan.jun. 1998 
Portanto, mesmo nos setores em que o estágio é legal e naqueles em que possa vir a ser legalizado, qualquer centro educacional não deve se furtar à tarefa de criar todos os mecanismos para propiciar aos estudantes a sua mais completa formação. No caso de um curso de Comunicação, significa, entre outras coisas, criar laboratórios que permitam esta produção e, especificamente, na relação com o público (fundamental para, aprendizado), um laboratório-veículo de comunicação. Esta ten sido, inclusive, uma exigência para a regulamentação dos cursos existentes no País. A rádio da Universidade Federal de Goiás, por exemplo, foi considerada laboratório para efeito de reconhecimento dos cursos de Jornalismo e Radialismo pelo Ministério da Educação.

Partimos, portanto, na Universidade Federal de Goiás, de uma realidade na qual a Rádio Universitária, com capacidade para emissão de sinais, já está inserida. Assim, a emissora, como único veículo de massa da UFG, deve ter prioridade sobre os estágios empresariais. Isso significa que os estudantes interessados em complementar o aprendizado de sala de aula devem ser canalizados primeiro para o laboratório Rádio Universitária. Além das razões já apontadas, isso se justifica pelas seguintes:

- A relação com o mercado: a Rádio Universitária está, como qualquer outro veículo de comunicação de massa, no mercado. Então, por que fazer estágio em outra emissora de Rádio, por exemplo, e não atividade laboratorial na Universitária? Por estar no mercado, permite, inclusive, o aprendizado dos aspectos essenciais a qualquer veículo (rádio, TV, jornal, internet).

- A qualidade: como atividade laboratorial e não simplesmente estágio, o aprendizado do aluno é muito maior na Universitária. $\mathrm{O}$ depoimento dos estudantes que passam por estágios em empresas comerciais tem demonstrado isso. Na Universitária, o trabalho é acompanhado por professor, enquanto na maioria das empresas comerciais não há qualquer acompanhamento e, quando ocorre, é por um profissional muitas vezes mal-remunerado e mal-humorado. Na Universitária, há mais espaço para a experimentação, para o exercício em múltiplas funções. 
- Uma maior estabilidade da mão-de-obra: se a Universidade deve intermediar a relação do estudante com o mercado, tem de preocupar-se, inclusive, com que isso se dê de forma a preservar os valores éticos. Uma destas formas é associar-se aos próprios egressos na luta contra o aviltamento do mercado de trabalho, contra a usurpação do direito ao trabalho profissional, contra a opressão sofrida por estes egressos, contra as atitudes antiéticas nas relações entre profissionais da comunicação, nas atitudes antiéticas dos empresários contra a dignidade dos trabalhadores deste setor. Isso significa criar condições para que os estudantes exerçam seu pleno direito ao aprendizado, sem criar obstáculos ao trabalho dos profissionais e, principalmente, ajudando a evitar que estes obstáculos se reflitam na qualidade da informação que chega à sociedade. A Rádio Universitária, bem como a TV Universitária, pode, e deve, ser um destes instrumentos. Isso significa fortalecer este laboratório, dando-lhe a infra-estrutura necessária (espaços para veiculação de programas, bolsas para os estudantes, designação de professores para acompanhar o trabalho).

\subsection{Reciclagem de aprendizado para professores}

A Fenaj - Federação Nacional dos Jornalistas - e a Enecos - Executiva Nacional dos Estudantes de Comunicação Social estão empenhadas na Campanha pela Melhoria da Formação Profissional dos Jornalistas.

Ưm dos tópicos desta proposta é a reciclagem na formação de professores. Propõem que os professores das disciplinas técnicas de Jornalismo (o que pode ser estendido para outros cursos) tenham sua carga horária diminuída por um determinado período para que, por meio de convênio, voltem à redação de empresas para passar por um processo de reciclagem, exercitando-se e acompanhando a produção que ali se processa, incluindo as novas tendências e a introdução de novas tecnologias.

Em grande parte, a Rádio e a TV Universitária podem ser estes veículos de reciclagem. Elas permitem o relacicnamento com o mercado e, desta forma, a sintonia com as novas tendências. $\mathrm{O}$ professor pode, também, voltar a exercitar elementos básicos

Comun. inf., v.1, n. 1, p. 153-166, jan./jun. 1998 
da produção em comunicação que valem, em determinado aspecto, para todos os meios (jornais, TVs, rádios), como o texto, a edição, a reportagem, a produção, a pauta etc).

\subsection{A pesquisa}

Os professores teóricos consideram laboratórios un atividade meramente técnica e portanto trabalham de costas para eles. E a maioria dos professores das chamadas disciplinas técnicas, por sua vez, trabalha de costas para a teoria. Este falso antagonismo só empobrece as duas práticas. Têmse que as rádios e TVs universitárias deixam de contribuir integralmente como laboratórios, na medida em que a sua prática deixa de ser refletida pelos teóricos e pelos técnicos. O que nos impede de cumprir com a nossa função de estar frente na proposição de novas formas de comunicação (novas linguagens, novas abordagens, novos conteúdos, novas formas de interação com a sociedade etc), a partir de pesquisas e experimentos realizados no interior de nossos laboratórios?

\subsection{O intercâmbio com outras universidades}

Estamos realizando uma experiência na nossa Universidade que tem se mostrado muito boa. Um dos programas laboratoriais na Rádio Universitária, o "Matéria-Prima", tem um quadro denominado Chamada a Cobrar, que é feito essencialmente por estudantes de outras universidades. Após uma vinheta que imita o sinal de chamada a cobrar do nosso sistema telefônico, estudantes/repórteres de outras universidades entram ao vivo, por telefone, falando dos principais acontecimentos de sua cidade, Estado ou região. Temos gente em Santa Maria-RS, Porto Alegre, Florianópolis, Rio de Janeiro, São Paulo, Brasília, Recife e São Luís do Maranhão.

Esta é mais uma experiência interessante que pode ser implementada pelas universidades, por meio de suas emissoras/ laboratórios. Com ela, pode-se ir além da inter e da multidisciplinaridade: é possível a troca inter-regional de experiências.

Comun. inf., v.1, n. 1, p. 153-166, jan.jun. 1998 


\section{Laboratório versus Estágio}

É preciso fazer a diferenciação conceitual para, inclusive, percebermos a discrepância prática, real. A rádio e a TV são veículos da própria Universidade, onde toda a sorte de experimentação é possível. Por isso, a atividade dos estudantes não pode ser conceituada e confundida com mero estágio, mas, sim, atividade laboratorial. Uma das conseqüências desta compreensão, além de todos os aspectos já enumerados, é que o tempo de permanência de um estudante neste laboratório pode, e deve, ser diferente do tempo estipulado para o estágio em empresas comerciais, porque este, em geral, tem suas normas e princípios filosóficos amarrados a preocupações mercadológicas.

Do ponto de vista pedagógico, há um grande ganho com esta compreensão e conceituação. Se tomada como atividade laboratorial imprescindível à qualidade dos cursos de comunicação e biblioteconomia, aumenta o nível de preocupação e envolvimento da instituição como um todo. A Faculdade se obriga a manter, permanentemente, oferta de vagas e programas para os estudantes, com o conseqüente aumento de envolvimento de professores e da estrutura administrativa. Conceituar o trabalho nestas emissoras como atividade laboratorial significa adequá-lo a uma realidade já presente e permite a sua evolução qualitativa.

\section{Tecnicismo versus teoria}

Como já apontei, a esmagadora maioria dos professores das cadeiras mais teóricas trabalha de costas para as chamadas disciplinas práticas ou técnicas e os titulares destas não refletem teoricamente a prática. Isso cria nas escolas de Comunicação um abismo profundo, que pode mergulhá-las numa prática pobre ou, na melhor das hipóteses, aquém de suas possibilidades.

E este comportamento transfere-se, também, para a relação dos estudantes com os seus laboratórios e oferece um sério risco para a qualidade do processo de ensino-aprendizagem. Quando não há laboratórios, os alunos tendem ao desânimo com o seu curso. Por outro lado, quando existem e, sobretudo, se são bons, o efeito não é menos perigoso: há o risco da supervalorização,

Comun. inf., v.1, n. 1, p. 153-166, jan./jun. 1998 
em detrimento do estudo teórico. Se não forem tomados os devidos cuidados, os laboratórios tendem a se transformar em espaço lúdico e os cursos podem vir a tornar-se meramente tecnicistas. Então, o fato de defender veementemente a existência dos laboratórios, e com qualidade, como defendo, não pode ser confundido com desprezo ou descuido em relação à formação humanística/teórica.

\section{As rádios e TVs universitárias e a democratização da comunicação e do conhecimento}

Emitindo sinais, os veículos universitários não podem ser considerados apenas formadores de profissionais e instrumentos para aprimorar a política de extensão da Universidade. Mesmo nas escolas particulares, são fruto de concessão pública. Portanto, têm de se prestar a projetos sociais, que contribuam para que a população possa exercer plenamente a sua cidadania. O primeiro passo para isso é que o ser humano tenha acesso mínimo às informações de que precisa para nortear a sua conduta e as suas decisões.

Num mundo em que os veículos de comunicação se transformaram também em facilitadores do lucro, aos anunciantes e aos proprietários dos veículos, é mais relevante ainda o papel daqueles órgãos que, além de serem públicos por força de uma concessão, também o são por pertencerem diretamente a órgãos públicos (geralmente de caráter estatal). As rádios e TVs universitárias devem concorrer, portanto, no mercado de trabalho, com uma versão não mercantilizada da informação, oferecendo aos cidadãos uma alternativa clara de programação, quer diretamente informativa/noticiosa (factual), quer indiretamente, por meio de produção educativa, cultural e comunitária. Estes meios têm de se prestar, portanto, ao papel de democratizadores da comunicação. E isso inclui a atitude de abrirem-se também para a co-gestão com a sociedade, criando mecanismos de participação direta, talvez em forma de conselhos.

Muitos destes veículos ainda precisam avançar significativamente neste campo, abrindo-se, inclusive, para a própria comunidade da Universidade, permitindo a prática laboratorial, a pesquisa e a extensão universitária; em outras palavras, deixando de ser guetos

Comun. inf., v.1, n. 1, p. 153-166, jan.jjun. 1998 
de administradores (reitores, diretores) e de profissionais sem compromisso social que pensam que as emissoras devem ser apenas laboratórios do ego ou cabides de emprego. Não acho que a Universidade deva ser, além de formadora de mão-deobra, geradora direta de oportunidades de emprego. Precisa, isto $\operatorname{sim}$, do trabalho de profissionais da comunicação - radialistas, jornalistas, bibliotecários, técnicos operadores de mesas de som etc -, não para dar-lhes emprego e sim para oferecer trabalho de qualidade à população. É preciso, portanto, entre outros males, acabar com o ranço corporativista no interior das emissoras e colocá-las a serviço de um projeto maior: acadêmico, educativo, cultural e social, conforme as diretrizes básicas da Rádio Universitária de Goiânia ${ }^{5}$, definidas em seminário interno realizado em dezembro de 1996. Sem isso não será, jamais, uma rádio ou TV universitária.

\section{Abstract}

This article deals with the didactic use of academic radio and tclevision in teaching communication. The author discusses democratic progress in communication and the question of laboratory in the university.

Key words: academic radio and television; laboratory; communication teaching; democratic communication.

\section{Notas}

1. FREIRE, Paulo. Extensão ou Comunicação? 8. ed. Rio de Janeiro: Paz e Terra, 1985.

2. Ver, sobre o assunto, entre outros, FREITAG, Bárbara. A teoria critica ontem e hoje. 5. ed. São Paulo: Brasiliense, 1994 e FREITAG, Bárbara e ROUANET, Sérgio Paulo (Orgs.). Habermas. 2. ed. São Paulo: Ática, 1990.

3. BUARQUE DE HOLANDA, Aurélio. Dicionário Aurélio Básico da Lingua Portuguesa. Goiânia: Nova Fronteira/O Popular, 1997. p. 382.

4. MARQUES DE MELO, José. Por uma política pedagógica para os órgãos laboratoriais dos cursos de jornalismo; Laboratórios de jornalismo: conceitos e preconceitos. In: __ Comunicação: teoria e política. São Paulo: Summus, 1985.

5. RÁDIO UNIVERSITÁRIA DA UFG. Diretrizes Básicas. Goiânia: Cegraf/UFG, 1996.

Comun. inf., v.1, n. 1, p. 153-166, jan./jun. 1998 